\title{
The Clinical Characteristics and Prognosis of Different Age Patients with Lung Cancer
}

This article was published in the following Dove Press journal:

Cancer Management and Research

\author{
Xiaorao Chen ${ }^{1, *}$ \\ Xiaoling $\operatorname{Han}^{2, *}$ \\ Honglian Zhou ${ }^{3 * *}$ \\ Yahai Liang' \\ Zhong Huang' \\ Shujun $\mathrm{Li}^{1}$ \\ Yanming Lin' \\ Xiaobi Huang' \\ Jiancong $\mathrm{Wu}^{\prime}$ \\ Wenmei Su' \\ Zhennan Lai' \\ Zhixiong Yang ${ }^{\prime}$ \\ 'Department of Pulmonary Oncology, \\ Affiliated Hospital of Guangdong Medical \\ University, Zhanjiang 52400I, People's \\ Republic of China; ${ }^{2}$ Guangdong Medical \\ University, Zhanjiang 52400I, People's \\ Republic of China; ${ }^{3}$ Department of \\ Ultrasound, Guangdong Medical \\ University Affiliated Hospital, Zhanjiang \\ 52400 I, People's Republic of China \\ *These authors contributed equally to \\ this work
}

Objective: Cancer is closely related to age, and the incidence of cancer increases with age. However, there are few studies on the relationship between age and clinical characteristics of lung cancer.

Patients and Methods: We collected all the consecutive lung cancer cases from 2012 to 2017 in our hospital and divided them into 6 groups according to their ages: $\leq 40 \mathrm{y} / \mathrm{o}, 41 \sim 50$ $\mathrm{y} / \mathrm{o}, 51 \sim 60 \mathrm{y} / \mathrm{o}, 61 \sim 70 \mathrm{y} / \mathrm{o}, 71 \sim 80 \mathrm{y} / \mathrm{o}$ and $>80 \mathrm{y} / \mathrm{o}$. The clinical characteristics and prognosis of these patients were evaluated.

Results: There were 1143 cases diagnosed in our hospital from 2012 to 2017 . There were more non-smokers $(\mathrm{p}<0.01)$, stage IV $(\mathrm{p}<0.01)$ and anaplastic lymphoma kinase (ALK) fusion $(\mathrm{p}<0.01)$ patients but less stage I patients in $\leq 40 \mathrm{y} / \mathrm{o}$ group compared with other age groups. It seemed that older patients were more likely had co-exist driver gene mutations $(p=0.04)$. There was no significant difference in overall survival (OS) among these 6 age groups. However, the age may be an independent prognostic factor compared with the patients in $\leq 40 \mathrm{y} / \mathrm{o}$ group, the patients in $>80 \mathrm{y} / \mathrm{o}$ group were associated with a higher mortality risk, while the patients in other groups had the similar mortality risk.

Conclusion: There are some differences in clinical characteristics and prognosis among different age groups. The reasons behind the phenomenon are largely unclear. The age should be taken into account when we develop clinical trials.

Keywords: age, lung cancer, clinical characteristics, clinical trials

\section{Introduction}

Age is one of the main factors in the onset of cancer. The incidence of cancer increases with age. The incidence rate increases rapidly from the age of 40 to the peak in the 80-year-old age group in the Chinese population. Most patients with lung cancer were older than 60 -year-old ${ }^{1}$. With the increase of age, the individuals are exposed to various risk factors for a longer time, which will lead to the accumulation of essential factors such as genetic mutations. ${ }^{2-4}$ These will lead to the occurrence of cancers. The high incidences of age are different among different cancers. ${ }^{5}$ Each cancer tends to be high in its high-risk age, while the incidence in other age groups is relatively low. Cancers of different ages may have different genetic status, such as young lung cancer, which is more prone to be with anaplastic lymphoma kinase (ALK) fusion. ${ }^{6,7}$ These suggest that age is closely related to cancers. Cancer patients of different age may have different clinical features and prognosis. However, there are few studies on the different clinical features of lung cancer patients among different age groups. Only some articles concluded that age was correlated to clinical features and prognosis as a subgroup result. ${ }^{8,9}$ The
Correspondence: Zhixiong Yang; Zhennan Lai

Tel +86I3802822690; +86I38225269l8

Email yangzhixiong068@I26.com;

laizhenn@I63.com 
morbidity and mortality of lung cancer in China are the highest in cancer, which seriously threatens people's health and is a huge social burden. ${ }^{10} \mathrm{We}$ intend to analyze the differences among different age groups of lung cancer from both clinical features and prognosis, which may give us some introductions during clinical practice and clinical trials.

\section{Patients and Methods}

We collected all patients diagnosed with lung cancer from 2012 to 2017 at Guangdong medical university, which was approved by the ethics committee of Guangdong medical university. All patients signed the consent statements to review their medical records when they were admitted to hospital. There are many large-scale randomized controlled clinical trials on lung cancer screening, with the starting and stopping ages of screening ranging from 47 to 60 years old and 69 to 80 years old, respectively. ${ }^{11-13}$ At present, there is no consistent conclusion on the starting and stopping screening age, and each guideline including the National Comprehensive Cancer Network (NCCN), European Society for Medical Oncology (ESMO) and Chinese Society of Clinical Oncology (CSCO), is slightly different. We divided the patients into 6 groups according to the starting and stopping ages of screening as mentioned above: $\leq 40 \mathrm{y} / \mathrm{o}, 41 \sim 50 \mathrm{y} / \mathrm{o}, 51 \sim 60 \mathrm{y} / \mathrm{o}, 61 \sim 70 \mathrm{y} / \mathrm{o}, 71 \sim 80$ $\mathrm{y} / \mathrm{o}$ and $>80 \mathrm{y} / \mathrm{o}$. There were 66 patients in $\leq 40 \mathrm{y} / \mathrm{o}$ group, 185 patients in 41 50 y/o group, 369 patients in 51 60 y/o group, 324 patients in $61 \sim 70 \mathrm{y} / \mathrm{o}$ group, 178 patients in $70 \sim 80$ y/o group and 21 patients in $>80$ y/o group.

There were 344 patients who underwent next generation sequencing (NGS) covering 12 driver genes: EGFR/KRAS/ ALK/PTEN/PI3K/cMET/STK11/BRAF/HER2/MEK1/

NF1/RET/AKT1. We defined a patient had more than one driver gene mutation as having co-exist driver gene mutations. We analyzed the gene profiles of patients in different groups. Chi-square tests were used to compare different clinical features (gender, cigarette smoking history, family cancer history, Eastern Cooperative Oncology Group performance status [ECOG PS], stage, pathology, epidermal growth factor receptor [EGFR] status, ALK status and target therapy) among different age groups. Overall survival (OS) was estimated using the Kaplan-Meier method, and the difference in survival between the subgroups was compared using a Log rank test. Univariate Cox regression analysis was used first to assess the association between each variable and survival, followed by multivariate stepwise Cox regression analysis for variable selection (with entry cutoff level of
0.4 and stay cutoff 0.1 ) We defined a patient had a family cancer history as a history of malignancy in first- to thirddegree relatives. The rational target therapy means that the patients have driver genes change and received corresponding target therapy and the patients neither have driver genes change nor received corresponding target therapy. The irrational target therapy means that the patients have driver genes change but did not received corresponding target therapy and the patients have not driver genes change but received corresponding target therapy. All analyses were performed using the SPSS 17.0 software program. All statistical tests were two-sided, and $P<0.05$ was deemed to indicate statistical significance.

\section{Results \\ Clinical Features}

There were 1143 consecutive lung cancer cases were collected from 2012 to 2017 . The clinical characteristics of cases in different age groups are shown in Table 1. Compared with other groups, there were more nonsmokers $(\mathrm{p}<0.01)$, stage IV $(\mathrm{p}<0.01)$ and ALK fusion $(\mathrm{p}<0.01)$ patients but less stage I patients in $\leq 40$ and 41-50 y/o groups. Other clinical factors such as gender, family history, ECOG PS, pathology, EGFR status and target therapy were balanced between different age groups.

\section{The Driver Gene Mutations in Different Age Groups}

There were 344 patients who received NGS including 12 driver genes as mentioned above. The most common gene alteration in different age groups was EGFR mutation. There were $2(7.4 \%)$ patients had co-exist driver gene mutations in $\leq 40 \mathrm{y} / \mathrm{o}$ group, $6(7.5 \%)$ in $41-50 \mathrm{y} / \mathrm{o}$ group, $10(8.5 \%)$ in $51-60$ y/o group, $6(8.6 \%)$ in $61-70$ y/o group, 5 (12.5\%) in 71-80 y/o group and $4(40.0 \%)$ in $>80 \mathrm{y} / \mathrm{o}$ group. It seemed that older patients were more likely had co-exist driver gene mutations $(\mathrm{p}=0.04)$.

\section{Survival Analysis}

The median follow-up time was 37.4 months. As the last follow-up time, a total of 567 patients had died. As shown in Figure 1, the median OS (mOS) was 31.3 months (95\% CI: $17.6-45.0$ months) in $\leq 40 \mathrm{y} / \mathrm{o}$ group. The mOS was 28.4 months (95\% CI: $24.5-32.3$ months) in $41 \sim 50 \mathrm{y} / \mathrm{o}$ group. The mOS was 29.8 months (95\% CI: $25.2-34.4$ months) in 51 60 y/o group. The mOS was 27.2 months (95\% CI: $21.9-32.5$ months) in $61 \sim 70 \mathrm{y} / \mathrm{o}$ group. The 
Table I The Clinical Characteristics of Different Age Groups

\begin{tabular}{|c|c|c|c|c|c|c|c|}
\hline & $\leq 40(66)$ & $41-50(185)$ & $51-60(369)$ & $61-70(324)$ & $71-80(178)$ & $>80(21)$ & $\mathbf{P}$ \\
\hline Gender & & & & & & & 0.61 \\
\hline Male & 40 & 114 & 212 & 199 & 116 & 14 & \\
\hline Female & 26 & 71 & 157 & 125 & 62 & 7 & \\
\hline Smoking status & & & & & & & $<0.01$ \\
\hline Smokers & 17 & 66 & 156 & 156 & 82 & 9 & \\
\hline Non-smokers & 49 & 119 & 213 & 168 & 96 & 12 & \\
\hline Family history & & & & & & & 0.06 \\
\hline Yes & 5 & 25 & 25 & 31 & 10 & 3 & \\
\hline No & 61 & 160 & 344 & 293 & 168 & 18 & \\
\hline ECOG PS & & & & & & & 0.07 \\
\hline$<2$ & 66 & 4 & 13 & 11 & 13 & 20 & \\
\hline$\geq 2$ & 0 & $18 \mid$ & 356 & 313 & 165 & I & \\
\hline Stage & & & & & & & $<0.01$ \\
\hline I & 3 & 19 & 57 & 68 & 35 & 4 & \\
\hline II & 3 & 7 & 32 & 24 & 11 & I & \\
\hline III & 8 & 47 & 84 & 66 & 35 & 3 & \\
\hline IV & 52 & 112 & 196 & 166 & 97 & 13 & \\
\hline Pathology & & & & & & & 0.10 \\
\hline$A D C$ & 59 & 158 & 286 & 258 & 137 & 16 & \\
\hline SCC & 3 & 15 & 54 & 35 & 30 & 3 & \\
\hline SCLC & 0 & 4 & 9 & 15 & 3 & 0 & \\
\hline Others & 4 & 8 & 20 & 16 & 8 & 2 & \\
\hline EGFR & & & & & & & 0.26 \\
\hline Wild type & 36 & 101 & 236 & 187 & 104 & 14 & \\
\hline Mutation & 30 & 84 & 133 & 137 & 74 & 7 & \\
\hline Alk & & & & & & & $<0.01$ \\
\hline Wild type & 57 & 162 & 347 & 311 & 173 & 21 & \\
\hline Fusion & 9 & 23 & 22 & 13 & 5 & 0 & \\
\hline Co-exist mutation & & & & & & & 0.04 \\
\hline Yes & 2 & 6 & 10 & 6 & 5 & 4 & \\
\hline No & 25 & 74 & 107 & 64 & 35 & 6 & \\
\hline Target therapy & & & & & & & 0.09 \\
\hline Rational & 46 & 116 & 278 & 230 & 127 & 15 & \\
\hline Irrational & 20 & 69 & 91 & 94 & 51 & 6 & \\
\hline
\end{tabular}

Abbreviations: ADC, adenocarcinomas; SCC, squamous cell carcinomas; SCLC, small cell lung cancer; EGFR, epidermal growth factor receptor; ALK, anaplastic lymphoma kinase.

mOS was 22.2 months (95\% CI: 16.6-27.8 months) in $71 \sim 80$ y/o group. The mOS was 29.9 months (95\% CI: $7.3-52.5$ months) in $>80 \mathrm{y} / \mathrm{o}$ group. There was no significant difference in OS among these 6 groups $(\mathrm{P}=0.369)$.

\section{Multivariate Stepwise Cox Regression Analysis}

Six of the eleven variables mentioned in the "patients and methods" section were found to be independent poor prognostic factors through a multivariate stepwise Cox regression analysis, as shown in Table 2. Compared with the patients in $\leq 40 \mathrm{y} /$ o group, the patients in $\geq 80 \mathrm{y} /$ o group were associated with a higher mortality risk, while the patients in other groups had the similar mortality risk. In reverse order by age, the hazard ratio (HR) of other five groups were $0.92(0.62-1.37, \mathrm{p}=1.37), 1.14(0.79-1.65$, $\mathrm{p}=0.49), \quad 1.33 \quad(0.92-1.94, \quad \mathrm{p}=0.13), \quad 1.34 \quad(0.90-2.00$, $\mathrm{p}=0.15)$ and $2.04(1.06-3.96, \mathrm{p}=0.34)$. The other factors 


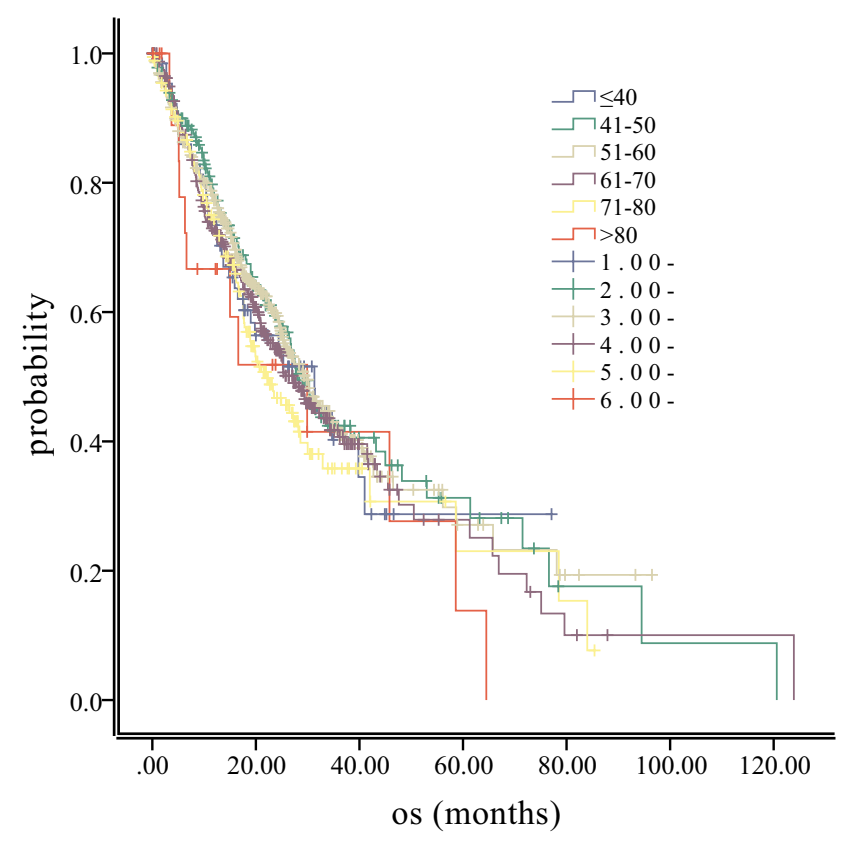

Figure I Survival analysis of patients among 6 age groups.

were associated with a lower mortality risk compared with the reference as shown in Table 2: PS $<2$, stage I, EGFR mutant and non-smokers.

\section{Discussion}

There are few studies on the different clinical features of lung cancer patients among different age groups. Our study found that there were more non-smokers, stage IV and ALK fusion patients but less stage I patients in $\leq 40 \mathrm{y} /$ o group compared with other age groups. It seemed that older patients were more likely had co-exist driver gene mutations. There was no significant difference in OS among these 6 age groups. However, the age may be an independent prognostic factor: compared with the patients in $\leq 40 \mathrm{y} / \mathrm{o}$ group, the patients in $>80 \mathrm{y} / \mathrm{o}$ group were associated with a higher mortality risk, while the patients in other groups had the similar mortality risk.

Smoking is a predisposing factor for lung cancer, but young people are more non-smokers, which is mainly affected by global smoking bans and people's awareness of the dangers of smoking. In recent years, great changes have taken place in China due to environmental factors such as haze caused by industrial development. The conclusion that air pollution causes cancer is drawn by WHO in 2013. The air particulate matter (including PM 2.5) is classified as a class I carcinogen. Chinas serious air pollution gradually increased from 2000. More and more studies now believe that haze will lead to an increased risk of
Table 2 Independent Poor Prognostic Factors from Multivariate Analysis

\begin{tabular}{|l|l|l|l|}
\hline & Hazard Ratio & $95 \%$ CI & $P$ \\
\hline Age & & & 0.02 \\
$\leq 40$ & 1.00 & - & - \\
$4 I-50$ & 0.92 & $0.62-1.37$ & 1.37 \\
$5 I-60$ & 1.14 & $0.79-1.65$ & 0.49 \\
6I-70 & 1.33 & $0.92-1.94$ & 0.13 \\
$7 I-80$ & 1.34 & $0.90-2.00$ & 0.15 \\
$>80$ & 2.04 & $1.06-3.96$ & 0.34 \\
\hline ECOG PS & & & $<0.01$ \\
$<2$ & 1.00 & - & - \\
$\geq 2$ & 1.84 & $1.27-2.68$ & \\
\hline Stage & & & $<0.01$ \\
I & 1.00 & - & - \\
II & 1.87 & $0.95-3.69$ & 0.07 \\
III & 5.47 & $3.31-9.05$ & $<0.01$ \\
IV & 12.6 & $7.8 I-20.22$ & $<0.01$ \\
\hline Pathology & & & 0.03 \\
ADC & 1.00 & & \\
SCC & 1.00 & $0.75-1.33$ & 1.00 \\
SCLC & 2.01 & $1.27-3.18$ & $<0.01$ \\
Others & 0.79 & $0.53-1.19$ & 0.26 \\
\hline EGFR & 1.00 & & $<0.01$ \\
Wild type & 0.58 & & \\
Mutation & 1.00 & & $<0.01$ \\
\hline Smoke & 1.42 & & \\
No & & & \\
Yes & & & \\
\hline
\end{tabular}

Abbreviations: ECOG PS, Eastern Cooperative Oncology Group performance status; ADC, adenocarcinomas; SCC, squamous cell carcinomas; SCLC, small cell lung cancer; EGFR, epidermal growth factor receptor.

lung cancer. For example, the research by Guo et al showed that male residents in urban areas, in the lower economic or lower education counties were faced with a greater effect of PM2.5 on the incidence rate of lung cancer in China. ${ }^{14}$ Bai et al showed the positive associations of lung cancer incidence with PM2.5 and NO2 in the Ontario Population Health and Environment Cohort. ${ }^{15}$ This reminds us that the pathogenesis of young lung cancers and old ones may be different due to changes in external factors.

There were more stage IV patients in younger group may because health checkup for young people rarely contain screening for lung cancer. So, it's harder for young people to find out lung cancer in early stage. ALK rearrangements occur in $5-7 \%$ of NSCLC cases in East Asian 
countries. ${ }^{6}$ It has been reported that ALK rearrangement typically occurred in younger patients, which was also verified by our results.

Family history of cancer is a predisposing factor for cancers, ${ }^{16-20}$ including lung cancer. ${ }^{21,22}$ According to our results, there was no difference in family cancer history among different age groups. The result was not what we expected and was different from some other research results. For example, Lee et al concluded that patients with family history of pulmonary cancer had a higher proportion of young patients ( $\leq 45$ years) than those without the family history. ${ }^{23} \mathrm{Xu}$ et al proved in their study that the risk of lung cancer in the subjects with early-onset cancers ( $<50$ years) was higher than the later-onset cancers ( $\geq 50$ years), especially in individuals with family history of liver cancer (OR 9.24 vs 1.39). ${ }^{16}$ At present, most studies discuss the relationship between age and family cancer history from the perspective of family history, but few studies discuss family history from the perspective of age. The jury is still out on whether younger lung cancer is associated with more family cancer history. Whether the younger lung cancer patients were more likely to have a family cancer history is uncertain.

Cancer initiation and development are driven by key mutations in driver genes. The mutation spectrum may be different in different age groups. There were more diver gene mutations in older age groups, which may because the older ones were exposed to longer-term external factors. There were other similar results in other studies. Yokoyama et al found out that mutated clones emerge multifocally from early childhood and increase their number and size with ageing. ${ }^{24}$ Martincorena et al mapped mutant clones in normal esophageal epithelium from nine donors (age range, 20 to 75 years) and found that somatic mutations accumulated with age. ${ }^{25}$

There was no difference in single factor survival analysis among different age groups. However, age was an independent prognostic factor in multivariate survival analysis. This indicates that age is maybe a prognostic factor, but due to the influence of confounding factors in different age groups, the survival differences disappear. That indicated that age was not a strong prognostic factor. And our study included some small subsets, for example, SCLC histology and PS 2-4. The treatment strategy and prognosis of these subsets were considerably different. This may interfere our evaluation on the impact of age to the prognosis.

\section{Conclusions}

In summary, we identified the differences among different age groups in clinical characteristics and prognosis. However, the mechanisms behind this phenomenon were unclear. We can only speculate the causes of this phenomenon now, and it is worthy of our exploration in the future. Although the study is retrospective and spanned a long period of time in single center, the results have certain reference value and we should take age into account when we develop clinical trials.

\section{Funding}

This work was supported in part by the National Natural Science Foundation of China (NSFC) (81702270 to W.S.; 81871883 to Z.Y.; 81803564 to L.W.); Affiliated Hospital of Guangdong Medical University Doctoral Foundation (Grant No. 2018052638) to W.S.

\section{Disclosure}

The authors report no conflicts of interest in this work.

\section{References}

1. Bray F, Ferlay J, Soerjomataram I, Siegel RL, Torre LA, Jemal A. Global cancer statistics 2018: GLOBOCAN estimates of incidence and mortality worldwide for 36 cancers in 185 countries. CA Cancer J Clin. 2018;68(6):394-424. doi:10.3322/caac.21492

2. Stratton MR, Campbell PJ, Futreal PA. The cancer genome. Nature. 2009;458(7239):719-724. doi:10.1038/nature07943

3. Vogelstein B, Papadopoulos N, Velculescu VE, Zhou S, Diaz LA Jr., Kinzler KW. Cancer genome landscapes. Science. 2013;339 (6127):1546-1558. doi:10.1126/science. 1235122

4. Merlo LM, Pepper JW, Reid BJ, Maley CC. Cancer as an evolutionary and ecological process. Nat Rev Cancer. 2006;6(12):924-935. doi: $10.1038 / \mathrm{nrc} 2013$

5. Lin $\mathrm{HN}$, Gu XY, Zhang SW, Zeng HM, Wei WW, Zheng RS, [Analysis on incidence and mean age at diagnosis for Global Cancer]. Zhonghua Zhong Liu Za Zhi [Chin J Oncol]. 2018;40 (7):543-549. doi:10.3760/cma.j.issn.0253-3766.2018.07.012

6. Wu YL, Lu S, Lu Y, et al. Results of PROFILE 1029, a Phase III comparison of first-line crizotinib versus chemotherapy in East Asian patients with ALK-positive advanced non-small cell lung cancer. J Thorac Oncol. 2018;13(10):1539-1548. doi:10.1016/j.jtho.2018.06.012

7. Solomon BJ, Mok T, Kim DW, et al. First-line crizotinib versus chemotherapy in ALK-positive lung cancer. $N$ Engl $J$ Med. 2014;371(23):2167-2177. doi:10.1056/NEJMoa1408440

8. Takeuchi K, Soda M, Togashi Y, et al. RET, ROS1 and ALK fusions in lung cancer. Nat Med. 2012;18(3):378-381. doi:10.1038/nm.2658

9. Shaw AT, Yeap BY, Mino-Kenudson M, et al. Clinical features and outcome of patients with non-small-cell lung cancer who harbor EML4-ALK. J Clin Oncol. 2009;27(26):4247-4253. doi:10.1200/JCO.2009.22.6993

10. Chen W. Cancer statistics: updated cancer burden in China. Chin $J$ Cancer Res $=$ Chung-Kuo Yen Cheng Yen Chiu. 2015;27(1):1.

11. Gould MK, Donington J, Lynch WR, et al. Evaluation of individuals with pulmonary nodules: when is it lung cancer? Diagnosis and management of lung cancer, 3rd ed: American College of Chest Physicians evidence-based clinical practice guidelines. Chest. 2013;143(5 Suppl):e93S-e120S. doi:10.1378/chest.12-2351 
12. Field JK, Smith RA, Aberle DR, et al. International association for the study of lung cancer computed tomography screening workshop 2011 report. J Thorac Oncol. 2012;7(1):10-19. doi:10.1097/ JTO.0b013e31823c58ab

13. Wender R, Fontham ET, Barrera E Jr, et al. American cancer society lung cancer screening guidelines. CA Cancer J Clin. 2013;63 (2):107-117. doi:10.3322/caac.21172

14. Guo H, Chang Z, Wu J, Li W. Air pollution and lung cancer incidence in China: who are faced with a greater effect? Environ Int. 2019;132:105077. doi:10.1016/j.envint.2019.105077

15. Bai L, Shin S, Burnett RT, et al. Exposure to ambient air pollution and the incidence of lung cancer and breast cancer in the Ontario Population Health and Environment Cohort. Int J Cancer. 2020;146 (9):2450-2459. doi:10.1002/ijc.32575

16. Xu CR, Lin H, Su J, et al. Familial association of lung cancer with liver cancer in first-degree relatives. Cancer Manag Res. 2019;11:5813-5819. doi:10.2147/CMAR.S199462

17. Jacobs EJ, Rodriguez C, Newton CC, et al. Family history of various cancers and pancreatic cancer mortality in a large cohort. Cancer Causes Control. 2009;20(8):1261-1269. doi:10.1007/s10552-0099339-6

18. Bermejo JL, Sundquist J, Hemminki K. Sex-specific familial risks of urinary bladder cancer and associated neoplasms in Sweden. Int J Cancer. 2009;124(9):2166-2171. doi:10.1002/ijc.24178
19. Hiripi E, Lorenzo Bermejo J, Li X, Sundquist J, Hemminki K. Familial association of pancreatic cancer with other malignancies in Swedish families. $\mathrm{Br} J$ Cancer. 2009;101(10):1792-1797. doi:10.1038/sj.bjc. 6605363

20. Moghimi-Dehkordi B, Safaee A, Vahedi M, Pourhoseingholi MA, Pourhoseingholi A, Zali MR. Population prevalence of first- and second-degree family history of breast and ovarian cancer. East Afr J Public Health. 2011;8(4):275-277.

21. Fiederling J, Shams AZ, Haug U. Validity of self-reported family history of cancer: a systematic literature review on selected cancers. Int J Cancer. 2016;139(7):1449-1460. doi:10.1002/ijc.30203

22. Lin H, Huang YS, Yan HH, et al. A family history of cancer and lung cancer risk in never-smokers: a clinic-based case-control study. Lung Cancer. 2015;89(2):94-98. doi:10.1016/j.lungcan.2015.05.017

23. Lee Y, Jeon $\mathrm{JH}$, Goh $\mathrm{SH}$, et al. The clinical impact of family history of cancer in female never-smoker lung adenocarcinoma. Lung Cancer. 2019;136:15-22. doi:10.1016/j.lungcan.2019.07.031

24. Yokoyama A, Kakiuchi N, Yoshizato T, et al. Age-related remodelling of oesophageal epithelia by mutated cancer drivers. Nature. 2019;565(7739):312-317. doi:10.1038/s41586-018-0811-x

25. Martincorena I, Fowler JC, Wabik A, et al. Somatic mutant clones colonize the human esophagus with age. Science. 2018;362 (6417):911-917. doi:10.1126/science.aau3879

\section{Publish your work in this journal}

Cancer Management and Research is an international, peer-reviewed open access journal focusing on cancer research and the optimal use of preventative and integrated treatment interventions to achieve improved outcomes, enhanced survival and quality of life for the cancer patient.
The manuscript management system is completely online and includes a very quick and fair peer-review system, which is all easy to use. Visit http://www.dovepress.com/testimonials.php to read real quotes from published authors. 